\title{
Diabetes Mellitus and Associated Factors Among Adult HIV Patients on Highly Active Anti-Retroviral Treatment
}

\author{
Fanta Duguma (D' \\ Waqtola Gebisa (ID) \\ Aklilu Mamo id \\ Dessalegn Tamiru iD ${ }^{2}$ \\ Shiferaw Woyesa' \\ 'School of Medical Laboratory Sciences, \\ Faculty of Health Sciences, Jimma \\ University, Jimma, Ethiopia; ${ }^{2}$ Department \\ of Nutrition and Dietetics, Faculty of \\ Public Health, Jimma University, Jimma, \\ Ethiopia
}

This article was published in the following Dove Press journal: HIVIAIDS - Research and Palliative Care

Background: Highly active anti-retroviral therapy (HAART) prolongs the life span of people living with HIV (PLWHIV) and intensely reduces HIV-related morbidity and mortality. Globally, HIV-associated non-communicable diseases are becoming major public concerns, and chronic comorbidities have appeared as a substantial reason for morbidity and mortality in HIV patients with prolonged use of HAART.

Purpose: A cross-sectional study design was used to assess the magnitude of diabetes mellitus and risk factors among adult HIV patients exposed to HAART at Jimma Zone Public Hospitals from May to July 30, 2018.

Patients and Methods: A convenient sampling technique was used to include a total of 271 adult HIV patients on HAART visiting the selected health facilities at the time of data collection. Socio-demographic and clinical data were collected by interviewer-administered questionnaire and by reviewing patients' record data. Bivariate and multivariate logistic regressions were used to identify variables that are independent predictors for diabetes mellitus.

Results: The prevalence of diabetes and pre-diabetes among PLWHIV exposed to HAART was $11.4 \%$ and $16.6 \%$, respectively. The prevalence of diabetic dyslipidemia in PLWHIV exposed on HAART was $8.9 \%(n=24)$. Government workers (AOR: 0.17, 95\% C.I $=0.03-$ 0.85, $\mathrm{P}=0.031$ ), long duration in HAART use (AOR: 11.06, 95\% C.I:1.03-18.67, $\mathrm{P}=0.047$ ), hyper-triglyceridemia (AOR: 2.62,95\% C.I:0.82, 8.39, P=0.005), LDL-C < 130 mg/dl (AOR: 4.04, 95\% C.I $=1.33-12.30, \mathrm{P}=0.014$ ), and obesity (AOR: 9.62, 95\% C.I: $1.01-91.52$, $\mathrm{P}=0.049$ ) were independent risk factors for diabetes mellitus in PLWHIV exposed to HAART.

Conclusion: Exposure to HAART increased the prevalence of diabetes mellitus in PLWHIV although it enhances quality of life, improves immune functions and prevents the onset of opportunistic infections. Therefore, regular screening for blood glucose level for PLWHIV on HAART is advisable.

Keywords: diabetes mellitus, dyslipidemia, prevalence, HAART, risk factors

\section{Background}

Highly active anti-retroviral therapy (HAART) prolongs the life span of people living with HIV (PLWHIV) and intensely reduces HIV-related morbidity and mortality, improves the function of the immune system as well as reduces risk of opportunistic infections. ${ }^{1-3}$ Different HIV medicines have different side effects and some side effects like cholesterol increment can lead to problems that may not appear for months or years after starting the therapies. ${ }^{3,4}$ 
Diabetes mellitus among PLWHIV has increased with long-term exposure to HAART., ${ }^{5,6}$ Globally, HIV-associated non-communicable diseases are becoming major public concerns and chronic comorbidities have appeared as a substantial reason for morbidity and mortality in PLWHIV with prolonged use of HAART. ${ }^{6-8}$ Adults with diabetes are two to three times more likely to have rate of cardiovascular disease than adults without diabetes; and PLWHIV on HAART are exposed to diabetes earlier than non-HIV infected individuals, ${ }^{6,9}$ and are about four times more likely to develop diabetes mellitus than PLWHIV not on HAART. ${ }^{2,9-11}$

Majority of PLWHIV have lipodystrophy syndrome having central and visceral obesity that is related to diabetes mellitus. ${ }^{12}$ Some HAARTs are nucleotide reverse transcriptase inhibitors and the others are non-nucleotide reverse transcriptase inhibitors and the combination of the two is recommended as a first line regime. ${ }^{10,13}$ Protein inhibitors have various effects on glucose metabolism and some of them inhibit glucose transporter type 4 mediated glucose transport (indinavir and ritonavir) leading to insulin resistance and reduce the secretion of insulin by interfering with $\beta$-cell function. ${ }^{6,14}$ Some HIV protein inhibitors interfere with cellular retinoic acid-binding protein type 1 which interacts with and inhibits the peroxisomal proliferator-activated receptor- $\gamma$ whose inhibition leads to insulin resistance and release of free fatty acids that have great contribution to insulin resistance. ${ }^{8,15}$

Certain risk factors like family history of diabetes, weight gain, lipodystrophy, advance in age, and hepatitis $\mathrm{C}$ infection are among the identified risk factors for the development of diabetes mellitus among PLWHIV on protein inhibitor therapy. ${ }^{3,16}$ The exact mechanism how insulin resistance developed among PLWHIV exposed to HAART is not yet elucidated; however, endocrine abnormalities, viral and host factors are expected to reduce the effectiveness of insulin. ${ }^{16,17}$

The prevalence of diabetes mellitus in PLWHIV has been reported from the range of $2-14 \% .{ }^{10,18}$ Diabetes was not common among HIV infected treatment naïve subjects and its prevalence was about $2-2.6 \% ;{ }^{19}$ however, a number of cases with rapid onset of diabetes have been reported among HIV patients since initiation of first generation protein inhibitors. ${ }^{10,19-23}$ Diabetes-HIV co-existence is a major health challenge although the mortality rate is reduced and quality of life is improved in PLWHIV exposed to HAART. ${ }^{2}$
Therefore, this study was aimed to determine the prevalence of diabetes mellitus and risk factors among PLWHIV exposed to HAART.

\section{Patients and Methods}

This study was carried out in Jimma zone located to Southwest from capital city of Ethiopia, Addis Ababa. Jimma zone has different private and public health institutions at Jimma town and district areas. The two hospitals where this study conducted are located in Jimma town and the other two hospitals are located in two different districts of the zonal area. An institution-based cross sectional study design was conducted among four hospitals in the study area and a single population proportion formula was used to calculate the total number of sample size. The first hospital had been selected randomly and the study subjects were selected proportionally from each hospital and a convenient sampling technique was used to include a total of 271 adult HIV patients on HAART visiting the selected health facilities at the time of data collection. Adult HIV patients on HAART for 3 months being adherent to the treatment regime were included and those study subjects receiving lipid profile lowering therapies, pregnant, unable to give consent and have history of chronic hepatitis viral infection and thyroid diseases were excluded from the study. We used the information-motivation-behavioral skills (IMB) model to identify HAART adherence. $^{24}$

We developed questionnaire that had three parts, namely socio-demographic, clinical and substance use parts. Socio-demographic and substance use and data were collected by interviewer administered whereas patients' records were reviewed to collect all clinical data. The collected data were daily checked by principal investigators and any inconsistency would be corrected immediately before going to next step. Anthropometric data were collected by strictly following World Health Organization (WHO) Guidelines and Body Mass Index (BMI) was calculated by simple calculation formula: weight $(\mathrm{Kg}) /$ height (square meter) and BMI values between $25-29.9 \mathrm{~kg} / \mathrm{m}^{2}$ and greater than $30 \mathrm{~kg} / \mathrm{m}^{2}$ were taken as overweight and obesity respectively. In addition to BMI, we also measured Waist Circumference (WC) to assess obesity of each study subject by strictly following WHO guidelines and WC values greater than $102 \mathrm{~cm}$ for male and $88 \mathrm{~cm}$ for female were used as risk factor for obesity. ${ }^{25}$ Blood pressure measurement was also taken by clinical nurses to assess whether high blood pressure or 
hypertensive is the risk factor for diabetes mellitus in PLWHIV exposed to HAART. Study subjects with blood pressure measurement values between $170-180 \mathrm{mmHg}$ (systolic) and 100-110 $\mathrm{mmHg}$ (diastolic) were considered hypertensive.

\section{Laboratory Analysis}

Five milliliter fasting blood specimen had been collected by medical laboratory technologist at ART clinics of each zonal hospital and the serum was separated from whole blood within one hour of collection. Then, the serum sample would be checked visually for icterus (high concentration of bilirubin), hemolysis or turbidity (high concentration of lipid profile) that interferes with test values of lipid profile and glucose measurements.

Lipid profile like total cholesterol and triglyceride were measured directly in the serum by series of enzymatic reactions and high density lipoprotein cholesterol (HDL-C) was also measured directly in the serum using blocking reagents that reacts with apo-B containing lipoproteins including Chylomicrons (CM), very-low-density lipoproteins (VLDL) and low density lipoprotein (LDL) in which only HDL-C is detected under the assay conditions. LDL-C was calculated from measured values of TC, Tg and HDL-C by Friedewald equation according to their relation $[\mathrm{T} \mathrm{C}]=[$ VLDL-C $]+[$ LDL-C $]+[$ HDL-C $]$. Dyslipidemia or abnormal lipid metabolism was interpreted based on National cholesterol educational program: Adult Treatment Panel-III (NCEP: ATP-III): hypercholesterolemia ( $\mathrm{TC} \geq 200 \mathrm{mg} / \mathrm{dl}$ ), hypertriglyceridemia $(\mathrm{Tg} \geq 150 \mathrm{mg} / \mathrm{dl}$ ), abnormal HDL-C $\leq 40 \mathrm{mg} / \mathrm{dl}$ and abnormal LDL-C $\geq 130 \mathrm{mg} / \mathrm{dl}$. Blood glucose was measured enzymatically based on the basic test principle of glucose oxidase enzyme in which glucose oxidase oxidizes $\beta$-D-glucose into D-gluconic acid and hydrogen peroxide intermediate products, then hydrogen peroxide is coupled to the second reaction involving p-hydroxybenzoic acid and 4-aminoantipyrine in the presence of peroxidase with the formation of a quinoneimine dye complex that absorbs light at specific wave length, which is directly proportional to the concentration of glucose in the blood. The study subjects were considered to be diabetic when the blood glucose level was $\geq 126 \mathrm{mg} /$ $\mathrm{dl}$ in two occasions.

\section{Statistical Analysis}

All data were checked for consistency and completeness visually, then coded and entered into Epi-data version
4.02 and exported to SPSS version 20.0 for analysis. Categorical variables were analyzed using chi-square tests. Bivariate and multivariate logistic regression models were used to assess statistically significant association between independent and dependent variables. Those independent variables whose $\mathrm{P}$ value less than 0.25 in bivariate logistic regression model were moved to multivariate logistic regression to control possible confounder variables as well as to identify independent predictors at $\mathrm{P}<0.05$.

\section{Results}

Majority of the study subjects, $63.1 \%$, were females and the mean age of the study subjects was $38.5 \pm 8.98$ ranging from 19-66 years. About 3/4th of the study subjects were from urban and the rest from rural. From total 271 PLWHIV exposed on HAART, about $11.4 \%(n=31)$ had diabetes mellitus and none of them had known about their diabetic status before conducting this study. Impaired fasting glucose level or pre-diabetics was identified among 16.6\% study subjects and this indicates a substantial risk factor for type 2 diabetes mellitus (Figure 1).

The prevalence of diabetes was higher among urban dwellers as compared to rural (8.9\% versus $2.6 \%)$ respectively. From total study subjects diagnosed for diabetes mellitus, about $10.3 \%(\mathrm{n}=28)$ were smokers and also about the same proportion of diabetics were determined with no family history of diabetes. The highest prevalence of diabetes mellitus, 5.2\% $(n=14)$, was determined among $\mathrm{TDF}+3 \mathrm{TC}+\mathrm{EFV}$ HAART regime users and all AZT+3TC +ATV users had normoglycemic blood glucose level or non-diabetic. The prevalence of diabetes mellitus was highest, $11.1 \% \quad(n=30)$, among PLWHIV with clinical stage-I as compared with other clinical stages; and about $9.22 \%$ and $8.49 \%$ PLWHIV with duration of HIV and HAART $\geq 5$ years respectively were determined for diabetes mellitus. A higher prevalence of diabetes mellitus was determined among study subjects with hypercholesterolemia $(8.5 \%)$, hypertriglyceridemia $(8.1 \%)$ than other lipid profiles, and a lower overlapped prevalence of 7.4\% diabetes mellitus was indicated among PLWHIV with abnormal lipid profiles of both LDL-C and HDL-C. The prevalence of diabetic dyslipidemia and total dyslipidemia among PLWHIV exposed to HAART were $8.9 \%(n=24)$ and $32.5 \%(n=88)$ respectively (Table 1$)$.

Based on multivariate logistic regression, independent variables like being government workers, 


\title{
Prevalence
}

\author{
- Pre-diabetes/lmpaired fasting glucose \\ Diabetes Mellitus \\ - Diabetic dyslipidemia \\ - Total dyslipidemia
}

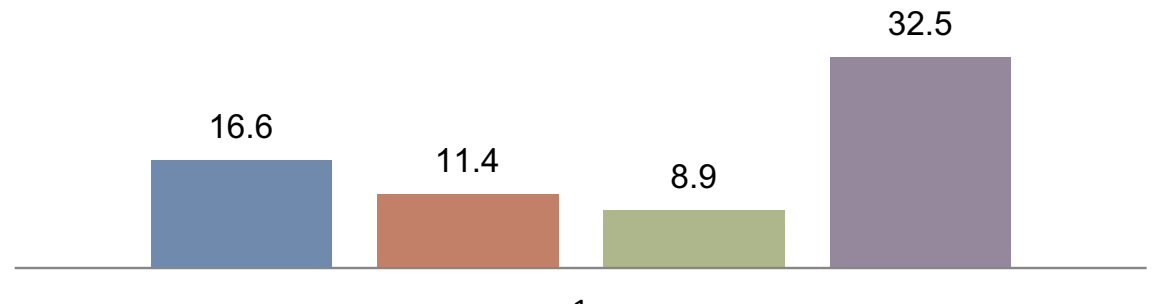

1

Figure I Prevalence of pre-diabetes, diabetes, diabetic dyslipidemia and total dyslipidemia in adult PLWHIV on HAART.

overweight or being obese, having abnormal level of LDL-C, hypertriglyceridemia and using HAART for greater than 6 years were determined risk factors in HAART users HIV patients to develop diabetes mellitus.
Overweight and obese HAART users were about 10.9 times (AOR: 10.90, $\mathrm{CI}=(1.35,87.79), \mathrm{P}=0.025)$ and 9.62 times (AOR: 9.62, C.I $=(1.01,91.52), \mathrm{P}=0.045)$ more likely to develop diabetes mellitus respectively

Table I Socio-Demographic and Clinical Characteristics of Adult PLWHIV on HAART

\begin{tabular}{|c|c|c|c|c|c|}
\hline \multirow[t]{2}{*}{ Variables } & \multirow[t]{2}{*}{ Categories } & \multicolumn{2}{|c|}{ Glucose Value (\%) } & \multirow[t]{2}{*}{ Total (\%) } & \multirow[t]{2}{*}{ P-value } \\
\hline & & Hyperglycemic & Normoglycemic & & \\
\hline \multirow[t]{2}{*}{ Age } & $<35$ years & $14(5.2)$ & $1 \mid 2(4 \mid .3)$ & $126(46.5)$ & \multirow[t]{2}{*}{0.039} \\
\hline & $\geq 35$ years & $17(6.3)$ & $128(47.2)$ & $145(53.5)$ & \\
\hline \multirow[t]{2}{*}{ Sex } & Male & $12(4.4)$ & $88(32.5)$ & $100(36.9)$ & \multirow[t]{2}{*}{0.676} \\
\hline & Female & $19(7.0)$ & $152(56.1)$ & $17 \mid(63.1)$ & \\
\hline \multirow[t]{4}{*}{ Occupation } & Farmer & $3(1.11)$ & $33(12.2)$ & $36(13.3)$ & \multirow[t]{4}{*}{0.140} \\
\hline & Employed & $17(6.3))$ & $7 I(26.2)$ & $88(32.5)$ & \\
\hline & Merchant & $3(1.11)$ & $48(17.7)$ & $5 I(18.8)$ & \\
\hline & Unemployed & $8(2.95))$ & $88(32.5)$ & $96(35.4)$ & \\
\hline \multirow[t]{2}{*}{ Residence } & Urban & $24(8.9)$ & $180(66.4)$ & $204(75.3)$ & \multirow[t]{2}{*}{0.953} \\
\hline & Rural & $7(2.6)$ & $60(22.1)$ & $67(24.7)$ & \\
\hline \multirow[t]{4}{*}{ Educational status } & Illiterate & $6(2.2)$ & $50(18.5)$ & $56(20.7)$ & \multirow[t]{4}{*}{0.395} \\
\hline & Primary school & 10(3.7) & $107(39.5)$ & $117(43.2)$ & \\
\hline & High school & $8(2.95)$ & $46(17.0)$ & $54(19.9)$ & \\
\hline & Diploma and above & $7(2.6)$ & $37(13.7)$ & $44(16.2)$ & \\
\hline \multirow[t]{4}{*}{ Marital status } & Married & $18(6.6)$ & I34(49.4) & $152(56.1)$ & \multirow[t]{4}{*}{0.727} \\
\hline & Not married & $2(0.74)$ & $24(8.9)$ & $26(9.6)$ & \\
\hline & Widowed & $6(2.2)$ & $44(16.2)$ & $36(13.3)$ & \\
\hline & Divorced & $5(1.8)$ & $52(19.2)$ & $57(21.0)$ & \\
\hline \multirow[t]{2}{*}{ Family history of diabetes } & Yes & $3(1.11)$ & $10(3.7)$ & $13(4.8)$ & \multirow[t]{2}{*}{0.140} \\
\hline & No & $28(10.3)$ & $230(84.9)$ & $258(95.2)$ & \\
\hline
\end{tabular}

(Continued) 
Table I (Continued).

\begin{tabular}{|c|c|c|c|c|c|}
\hline \multirow[t]{2}{*}{ Variables } & \multirow[t]{2}{*}{ Categories } & \multicolumn{2}{|c|}{ Glucose Value (\%) } & \multirow[t]{2}{*}{ Total (\%) } & \multirow[t]{2}{*}{ P-value } \\
\hline & & Hyperglycemic & Normoglycemic & & \\
\hline Smoking & $\begin{array}{l}\text { Yes } \\
\text { No }\end{array}$ & $\begin{array}{l}28(10.3) \\
3(1 . I I)\end{array}$ & $\begin{array}{l}213(78.6) \\
27(9.9)\end{array}$ & $\begin{array}{l}24 I(88.9) \\
30(I I . I)\end{array}$ & 0.291 \\
\hline HAART type & $\begin{array}{l}A Z T+3 T C+N V P \\
T D F+3 T C+E F V \\
A Z T+3 T C+E F V \\
T D F+3 T C+N V P \\
A Z T+3 T C+A T V / r \\
D F+3 T C+A T V\end{array}$ & $\begin{array}{l}6(2.21) \\
14(5.2) \\
3(1.11) \\
4(1.48) \\
0(0.0) \\
4(1.48)\end{array}$ & $\begin{array}{l}61(22.5) \\
114(42.1) \\
24(8.9) \\
19(7.0) \\
13(4.8) \\
9(3.3)\end{array}$ & $\begin{array}{l}67(24.7) \\
128(47.2) \\
27(10.0) \\
23(8.5) \\
13(4.8) \\
13(4.8)\end{array}$ & 0.543 \\
\hline WHO clinical Stage of AIDS & $\begin{array}{l}\text { I } \\
\text { II } \\
\text { III }\end{array}$ & $\begin{array}{l}30(I I . I) \\
\mathrm{I}(0.36) \\
0(0.0)\end{array}$ & $\begin{array}{l}224(82.7) \\
15(5.5) \\
(0.0)\end{array}$ & $\begin{array}{l}254(93.7) \\
\mathrm{I} 6(5.9) \\
\mathrm{I}(0.4)\end{array}$ & 0.785 \\
\hline Duration HIV & $\begin{array}{l}<5 \text { years } \\
\geq 5 \text { years }\end{array}$ & $\begin{array}{l}6(2.21) \\
25(9.22)\end{array}$ & $\begin{array}{l}70(25.8) \\
170(62.7)\end{array}$ & $\begin{array}{l}76(28.0) \\
195(72.0)\end{array}$ & 0.383 \\
\hline Duration of HAART & $\begin{array}{l}<5 \text { years } \\
\geq 5 \text { years }\end{array}$ & $\begin{array}{l}8(2.95) \\
23(8.49)\end{array}$ & $\begin{array}{l}89(32.8) \\
151(55.7)\end{array}$ & $\begin{array}{l}97(35.8) \\
174(64.2)\end{array}$ & 0.237 \\
\hline BMI & $\begin{array}{l}\text { Underweight } \\
\text { Normal } \\
\text { Overweight } \\
\text { Obese }\end{array}$ & $\begin{array}{l}I(0.37) \\
19(7.01) \\
7(2.6) \\
4(1.48)\end{array}$ & $\begin{array}{l}45(16.6) \\
157(57.9) \\
32(11.8) \\
6(2.2)\end{array}$ & $\begin{array}{l}46(17) \\
176(64.9) \\
44(16.2) \\
10(3.7)\end{array}$ & 0.0023 \\
\hline Hypertension & $\begin{array}{l}\text { Yes } \\
\text { No }\end{array}$ & $\begin{array}{l}6(2.21) \\
25(9.2)\end{array}$ & $\begin{array}{l}15(5.5) \\
225(83.0)\end{array}$ & $\begin{array}{l}21(7.7) \\
250(92.3)\end{array}$ & 0.0011 \\
\hline Waist circumference & $\begin{array}{l}\text { Normal } \\
\text { Abnormal }\end{array}$ & $\begin{array}{l}14(5.2) \\
17(6.3)\end{array}$ & $\begin{array}{l}185(68.3) \\
55(20.3)\end{array}$ & $\begin{array}{l}199(73.4) \\
72(26.6)\end{array}$ & 0.016 \\
\hline Waist to Hip Ratio & $\begin{array}{l}\text { Normal } \\
\text { Abnormal }\end{array}$ & $\begin{array}{l}8(2.9) \\
23(4.5)\end{array}$ & $\begin{array}{l}88(32.5) \\
152(56.1)\end{array}$ & $\begin{array}{l}96(35.4) \\
175(64.6)\end{array}$ & 0.650 \\
\hline $\mathrm{TC}(\geq 200 \mathrm{mg} / \mathrm{dl})$ & $\begin{array}{l}\text { Normal } \\
\text { Abnormal }\end{array}$ & $\begin{array}{l}8(2.9) \\
23(8.5)\end{array}$ & $\begin{array}{l}193(71.2) \\
47(17.3)\end{array}$ & $\begin{array}{l}201(74.2) \\
70(25.8)\end{array}$ & 0.001 \\
\hline Triglycerides $(\geq 150 \mathrm{mg} / \mathrm{dl})$ & $\begin{array}{l}\text { Normal } \\
\text { Abnormal }\end{array}$ & $\begin{array}{l}9(3.3) \\
22(8.1)\end{array}$ & $\begin{array}{l}191(70.5) \\
49(18.1)\end{array}$ & $\begin{array}{l}200(73.8) \\
7 I(26.2)\end{array}$ & 0.001 \\
\hline LDL-C( $(\geq 130$ mg/dl) & $\begin{array}{l}\text { Normal } \\
\text { High }\end{array}$ & $\begin{array}{l}11(4.1) \\
20(7.4)\end{array}$ & $\begin{array}{l}210(77.5) \\
30(11.1)\end{array}$ & $\begin{array}{l}221(81.5) \\
50(18.5)\end{array}$ & 0.001 \\
\hline HDL-C & $\begin{array}{l}\text { High } \\
\text { Low }\end{array}$ & $\begin{array}{l}I I(4.1) \\
20(7.4)\end{array}$ & $\begin{array}{l}45(16.6) \\
195(71.9)\end{array}$ & $\begin{array}{l}56(20.6) \\
215(79.4)\end{array}$ & 0.093 \\
\hline Dyslipidemia & $\begin{array}{l}\text { Yes } \\
\text { No }\end{array}$ & $\begin{array}{l}24(8.9) \\
7(2.6)\end{array}$ & $\begin{array}{l}64(23.6) \\
176(64.9)\end{array}$ & $\begin{array}{l}88(32.5) \\
183(67.5)\end{array}$ & 0.001 \\
\hline
\end{tabular}

Abbreviations: ABC, abacavir; AZT, zidovudine; cART, combined antiretroviral therapy; D4T, stavudine; DDI, didanosine; EFV, efavirenz; IDV, indinavir; LCF, lipid clearing factor; 3TC, lamivudine; NVP, nevirapine; TDF, tenofovir disoproxil fumarate; TC, total cholesterol; LDL-C, low-density lipoprotein cholesterol; HDL-C, high-density lipoprotein cholesterol; BMI, body mass index.

than others. Similarly, HAART users PLWHIV with abnormal LDL-C level were about 4.04 times more likely to develop diabetes mellitus (AOR: 4.04, C.I= $(1.33,12.30), \quad \mathrm{P}=0.014)$ than those with normal
LDL-C. Those PLWHIV with hyper-triglyceridemia (AOR: 2.62, 95\% C.I:0.82, 8.39, P: 0.005) were about 2.6 times more likely to develop diabetes than those with normal serum triglyceride concentration (Table 2). 
Table 2 Bivariate and Multivariate Logistic Regression

\begin{tabular}{|c|c|c|c|c|}
\hline Variables & $\operatorname{COR}(95 \% \mathrm{Cl})$ & P-value & AOR (95\% Cl) & P-value \\
\hline \multicolumn{5}{|l|}{ Occupational status } \\
\hline Farmer & $0.69(0.13,3.62)$ & 0.658 & $0.32(0.04,2.43)$ & 0.268 \\
\hline Government worker & $0.26(0.07,0.94)$ & 0.040 & $0.17(0.03,0.85)$ & 0.031 \\
\hline Unemployed & $0.69(0.17,2.7 I)$ & 0.593 & $0.40(0.08,2.12)$ & 0.284 \\
\hline Merchant & I & & I & \\
\hline \multicolumn{5}{|l|}{ Duration of HAART } \\
\hline $0-2$ & 1 & & 1 & \\
\hline $3-5$ & $4.42(0.57,34.01)$ & 0.154 & $0.87(0.29,2.62)$ & 0.799 \\
\hline$\geq 6$ & $1.31(0.53,3.20)$ & 0.560 & $11.06(1.03,118.67)$ & 0.047 \\
\hline \multicolumn{5}{|l|}{ Family History of DM } \\
\hline Yes & $0.4 \mathrm{I}(0.1 \mathrm{I}, \mathrm{I} .56)$ & 0.190 & $0.25(0.05,1.30)$ & 0.100 \\
\hline No & I & & I & \\
\hline \multicolumn{5}{|l|}{ Body mass index (BMI) } \\
\hline Normal & 1 & & 1 & \\
\hline Overweight & $6.28(1.61,24.45)$ & 0.008 & $10.90(1.35,87.79)$ & 0.025 \\
\hline Obese & $3.56(0.77,16.52)$ & 0.106 & $9.62(1.01,91.52)$ & 0.049 \\
\hline \multicolumn{5}{|l|}{ Dyslipidemia } \\
\hline Yes & $0.1 I(0.05,0.26)$ & 0.001 & $1.14(0.11,11.69)$ & 0.911 \\
\hline No & 1 & & 1 & \\
\hline \multicolumn{5}{|l|}{ Blood pressure } \\
\hline Normal & I & & I & \\
\hline Hypertensive & $2.22(0.69,7.18)$ & 0.182 & $0.62(0.13,2.92)$ & 0.545 \\
\hline \multicolumn{5}{|l|}{ Cholesterol } \\
\hline Normal & I & & 1 & \\
\hline Abnormal & $10.65(4.50,25.23)$ & 0.001 & $3.28(0.39,27.53)$ & 0.275 \\
\hline \multicolumn{5}{|l|}{ LDL-C } \\
\hline Normal & I & & 1 & \\
\hline Abnormal & $9.37(4.16,21.10)$ & 0.001 & $4.04(1.33,12.30)$ & 0.014 \\
\hline \multicolumn{5}{|l|}{ High density lipoprotein } \\
\hline Normal & 1 & & I & \\
\hline Abnormal & $0.42(0.19,0.94)$ & 0.001 & $0.89(0.27,2.94)$ & 0.850 \\
\hline \multicolumn{5}{|l|}{ Triglyceride } \\
\hline Normal & I & & I & \\
\hline Abnormal & $8.22(3.58,18.89)$ & 0.001 & $2.62(0.82,8.39)$ & 0.105 \\
\hline \multicolumn{5}{|l|}{ Waist circumference } \\
\hline Normal & $4.25(1.96,9.19)$ & 0.001 & $1.20(0.37,3.84)$ & 0.765 \\
\hline Abnormal & I & & 1 & \\
\hline \multicolumn{5}{|l|}{ Waist to HIP Ratio } \\
\hline Normal & I.66(0.7I, 3.88) & 0.238 & $0.70(0.22,2.25)$ & 0.554 \\
\hline Abnormal & I & & I & \\
\hline
\end{tabular}

Abbreviations: AOR, adjusted odds ratio; COR, crude odds ratio; $\mathrm{Cl}$, confidence interval; LDL, low-density lipoprotein.

\section{Discussion}

The overall prevalence of diabetes mellitus among PLWHIV exposed to HAART was $11.4 \%$ which is higher than the finding reported from Eastern Ethiopia which was $7.1 \%{ }^{26}$ and twice higher than the prevalence reported from Uganda which was $4.7 \%{ }^{27}$ Similarly, the 
prevalence of diabetes mellitus in this finding was higher than three findings reported from North Ethiopia which were $8.8 \%,{ }^{8} 11.8 \%{ }^{28}$ and $8.0 \%{ }^{29}$ In contrast to other studies with less prevalence of diabetes mellitus in PLWHIV on HAART than the current findings, one study revealed higher prevalence of diabetes mellitus, $14.9 \%$ among PLWHIV exposed to HAART. ${ }^{30}$ The smaller in sample size could be one reason for the higher prevalence of of diabetes mellitus in different studies than the prevalence of diabetes mellitus reported from the current study. The other possible reason might be the duration and regime of HAART used by PLWHIV. Those PLWHIV who used HAART for longer period of time could develop diabetes mellitus faster than those with shorter period of time. A study reported from Northwest Ethiopia showed less prevalence (8.0\%) of diabetes in PLWHIV exposed to HAART as compared to the prevalence reported in this study. ${ }^{31}$ The prevalence of diabetes in this finding was about two times more than the prevalence of diabetes in PLWHIV on HAART reported from Asia-Pacific region. ${ }^{1}$ About $16.6 \%$ of PLWHIV had impaired fasting glucose or pre-diabetic; however, the finding reported from Portugal revealed $20.0 \%$ prevalence of pre-diabetes. ${ }^{29}$

Multivariate logistic regression analysis revealed being government worker, having high concentration level of LDL-C, hypertriglyceridemia and long duration of HAART using were independent risk factors for PLWHIV exposed to HAART to develop diabetes mellitus. In opposite to our findings, hypertriglyceridemia and BMI were identified as independent risk factors in the study reported from Eastern Ethiopia. ${ }^{26}$ Hypertension and exposure to HAART were identified as risk factors for diabetes mellitus. ${ }^{5}$ Again in contrast to our findings, the findings reported from north Ethiopia identified hypertriglyceridemia, age and educational status as independent risk factors for diabetes mellitus in PLWHIV exposed to HAART. $^{8}$ Similar to our findings, another study`s finding reported from north Ethiopia identified long duration of HAART usage as a risk factor for diabetes mellitus; however, advance in age ( $\geq 45$ years), hypertension and family history of diabetes were identified as independent risk factors for diabetes in contrast to the findings reported from our study. ${ }^{29}$ Study reported from Taiwan revealed that HAART increased the risk of diabetes and hypertensive PLWHIV were about five times more likely to be at risk of diabetes, unlike to the current study. ${ }^{5}$
Increasing age, male gender and BMI were identified as risk factors for diabetes mellitus in PLWHIV exposed to HAART; however, increase in age and gender was not identified as risk of diabetes in our study. ${ }^{32}$ The findings reported from Northwest Ethiopia identified factors like tertiary education, hypertriglyceridaemia, obesity and hypertension as risk factors for diabetes in PLWHIV exposed to HAART whereas educational status and high blood pressure were not associated with diabetes in our findings. ${ }^{1,31}$ Again the study reported from north-east Ethiopia showed older age, hypertension, a family history of diabetes and duration of HAART were independently associated with increased odds of diabetes in contrast to our findings where family history of diabetes was not an independent risk factor. ${ }^{28}$ There was not any HAART identified as independent risk factor for diabetes in our current study whereas the study reported from Botswana determined PLWHIV receiving efavirenz were about five times more likely to develop diabetes than other therapy receivers. ${ }^{30}$

\section{Conclusion}

Exposure to HAART increased the prevalence of diabetes mellitus in PLWHIV although it enhances quality of life, improves immune functions and prevents the onset of opportunistic infections. Overweight or being obese, having abnormal level of LDL-C, hypertriglyceridemia and using HAART for greater than 6 years were independent risk factors in HAART users PLWHIV to develop diabetes mellitus. Therefore, regular screening for blood glucose level and health information to reduce or avoid risk factors are advisable for PLWHIV exposed to HAART.

\section{Abbreviation}

AOR, adjusted odds ratio; BMI, body mass index; CM, chylomicron; HAART, highly active anti-retroviral therapy; HDL-C, high-density lipoprotein cholesterol; LDL-C, low-density lipoprotein cholesterol; NCEP, National cholesterol educational program; ATP-III, Adult Treatment Panel-III; PLWHIV, people living with human immunodeficiency virus; TC, total cholesterol; VLDL-C, very lowdensity lipoprotein cholesterol; WC, waist circumference; WHO, World Health Organization.

\section{Data Sharing Statement}

Data is available from corresponding author on reasonable request. 


\section{Ethical Statement and Consent to Participate}

The study has been conducted in accordance with the principles stated in the Declaration of Helsinki and accordingly an ethical approval was taken from Research Ethical Committee of Institute of Health Sciences of Jimma University to Jimma Zone Head Office and the Head office directed the letter of ethical approval to the clinical director's of each Zonal Hospital where the study would be conducted. Again, the permission letter was obtained from each clinical director office to the perspective nursing heads of the ART clinics in the Hospitals. Before any data collection, the aim and method of the study as well as the source of funds was clearly explained for the study subjects. Furthermore, the study subjects were informed that the data obtained from them were used only for this study purpose. They were also informed as they had full right to refuse or withdraw consent to participate at any time without reprisal. Finally, the data were collected from each study subject after informed consent had been obtained.

\section{Acknowledgments}

The authors would like to express their gratitude to Jimma University for financing this research project and Jimma University Medical Center for allowing certain laboratory equipments to perform laboratory analysis. We would also like to thank study participants who gave us valuable information.

\section{Author Contributions}

All authors contributed to data analysis, drafting or revising the article, have agreed on the journal to which the article will be submitted, gave final approval of the version to be published, and agree to be accountable for all aspects of the work.

\section{Funding}

This research project has been financially funded by Jimma University and provided certain laboratory equipments to perform laboratory analysis by Jimma University Medical Center.

\section{Disclosure}

All authors declared no competing interest in this work.

\section{References}

1. Ana RC, FLavia AM. A diabetes mellitus in HIV-infected patients: fasting glucose, A1c, or oral glucose tolerance test; which method to choose for the diagnosis? BMC Infect Dis. 2018;18(309):1-13.
2. Quin J. Diabetes and HIV. Clin Med (Northfield Il). 2014;14(6):667669. doi:10.7861/clinmedicine.14-6-667

3. WHO. Summary of the Global HIV Epidemic; 2018.

4. Sanjay K, Bharti K, Navneet A, et al. Understanding diabetes in patients with HIV/AIDS. Diabetol Metab Syndr. 2011;3(2):1-7.

5. Tierney L, Mcphee S, Paladakis M, et al. Current Medical Diagnosis and Treatment. International Edition. New York: Lange medical Books/McGraw-Hill; 2002:203-215.

6. Shih P, Chun Y. Risk of diabetes mellitus in HIV-infected patients receiving highly active antiretroviral therapy a nationwide population-based study. Medicine. 2018;97(36):1-7.

7. Chhoun P, Ngin C, Tuot $S$, et al. Non-communicable diseases and related risk behaviors among men and women living with HIV in Cambodia: findings from a cross-sectional study. Int $J$ Equity Health. 2017;16(125):1-12. doi:10.1186/s12939-017-0622-y

8. Temesgen F, Alemu G. Diabetes mellitus and its associated factors among human immunodeficiency virus-infected patients on anti-retroviral therapy in Northeast Ethiopia. BMC Res Notes. 2019;12 (372):1-7.

9. Andrew C, David AC. Adverse effects of antiretroviral therapy. Lancet. 2000;356:1423-1429.

10. Anne K, Marshall J, Todd TB, et al. Diagnosing and managing diabetes in HIV-infected patients: current concepts. Clin Infect Dis. 2015;60(3):453-462. doi:10.1093/cid/ciu779

11. Avari P, Devendra S. Human immunodeficiency virus and type 2 diabetes. London J Prim Care. 2017;9(3):38-42. doi:10.1080/ 17571472.2017.1302872

12. André PS, Anderson MN, Andiara S. Lipodystrophy diagnosis in people living with HIV/AIDS: prediction and validation of sex-specific anthropometric models. BMC Public Health. 2018;18(806): $1-14$.

13. Emile CN, Jean CK, Eugene S, et al. Diabetes and HIV. Curr Diab. 2018;18(125):1-8.

14. Aboud M, Elgalib A, Kulasegaram R, et al. Insulin resistance and HIV infection: a review. Int clin Pract. 2007;61(3):1463-1472.

15. Carl A, Copper D. Adverse effect of antiretroviral therapy. Lancet. 2000;356(9239):1423-1430. doi:10.1016/S0140-6736(00)02854-3

16. Grinspoon S, Carr A. Cardiovascular risk and body-fat abnormalities in HIV-infected adults. $N$ Engl J Med. 2005;6(1):48-62. doi:10.1056/ NEJMra041811

17. Kalra S, Agrawal N. Diabetes and HIV: current understanding and future perspectives. Curr Diab Rep. 2013;13(3):419-427. doi:10. 1007/s11892-013-0369-9

18. Behrens G, Stoll M, Schmidt R, et al. Lipodystrophy syndrome in HIV infection. What is it, what causes it and how can it be managed? Off J Int Soc Pharmacovigilance. 2000;23(1):57-76.

19. Maganga E, Smart L, Kalluvya S, et al. Glucose metabolism disorders, HIV and antiretroviral therapy among Tanzanian adults. PLoS One. 2015;10(8):1-10. doi:10.1371/journal.pone.0134410

20. Jerico C, Knobel H, Montero M, et al. Metabolic syndrome among HIV-infected patients: prevalence, characteristics and related factors. Diabetes Care. 2005;28(1):132-137. doi:10.2337/diacare.28.1.132

21. Miller J, Carr A, Emery S, et al. HIV lipodystrophy: prevalence, severity and correlates of risk in Australia. HIV Med. 2003;4(3):293301. doi:10.1046/j.1468-1293.2003.00159.x

22. Assane D, Amandine C, Khadidiatou B, et al. Diabetes and hypertension among patients receiving antiretroviral treatment since 1998 in Senegal. Int Sch Res Network. 2012;1-8.

23. Hejazi N, Rajikan R, Choong C, et al. Metabolic abnormalities in adult HIV infected population on antiretroviral medication in Malaysia: a cross-sectional survey. BMC Public Health. 2013;13 (1):1-11. doi:10.1186/1471-2458-13-758

24. Movahed E, Ali M, Farokhzadain J, et al. Antiretroviral therapy adherence among people living with HIV: directed content analysis based on information-motivation-behavioral skills model. Int $Q$ Community Health Educ. 2019;40(1):1-9. 
25. CDC. National Health and Nutrition Examination Survey (NHANES). Anthropometry Procedures Manual; 2007.

26. Zerihun A, Wondimye A. Magnitude and associated factors of diabetes mellitus and hypertension among adult HIV-positive individuals receiving highly active antiretroviral therapy at Jugal Hospital, Harar, Ethiopia. HIV AIDS (Auckl). 2018;10:181-192. doi:10.2147/HIV. S176877

27. Sheila K, Doris M. Prevalence of non-communicable diseases among HIV positive patients on antiretroviral therapy at joint clinical research centre, Lubowa, Uganda. PLoS One. 2019;14(8):1-11.

28. Alemu G, Bekele T. Diabetes mellitus and its associated risk factors in patients with human immunodeficiency virus on anti-retroviral therapy at referral hospitals of North West Ethiopia. Diabetol Metab Syndr. 2020;12(20):1-8.
29. Adeel A, Kathleen M. HIV infection and the risk of diabetes mellitus. AIDS. 2009;23:1227-1234. doi:10.1097/QAD.0b013e32832bd7af

30. Solomon M, Assefa G. Diabetes mellitus among HIV-infected individuals in follow-up care at University of Gondar Hospital, North west Ethiopia. BMJ. 2016;6:1-6.

31. Win M, Awachana J, Sasisopin K, et al. Diabetes mellitus burden among people living with HIV from the Asia-Pacific region. $J$ Int AIDS Soc. 2019;22:1-8.

32. Moyo D, Tanthuma G, Mushisha O, et al. Diabetes mellitus in HIVinfected patients receiving antiretroviral therapy. $S$ Afr Med J. 2014;104(1):37-39. doi:10.7196/samj.6792

HIV/AIDS - Research and Palliative Care

\section{Publish your work in this journal}

HIV/AIDS - Research and Palliative Care is an international, peerreviewed open-access journal focusing on advances in research in HIV, its clinical progression and management options including antiviral treatment, palliative care and public healthcare policies to control viral spread. The manuscript management system is completely online and includes a very quick and fair peer-review system, which is all easy to use. Visit http://www.dovepress.com/testimonials.php to read real quotes from published authors. 